\title{
Painless cervical motor radiculopathy relieved by cervical epidural steroid injection - A case report -
}

Received May 24, 2018

Revised 1st, July 3, 2018

2nd, July 13, 2018

Accepted July 13, 2018

\section{Corresponding author}

Sang-Soo Kang, M.D., Ph.D.

Department of Anesthesiology and

Pain Medicine, Kangdong Sacred

Heart Hospital, 150 Seongan-ro,

Gangdong-gu, Seoul 05355, Korea

Tel: 82-2-2224-2659

Fax: 82-2-474-0956

E-mail: kssege@naver.com

ORCID

https://orcid.org/0000-0002-9347-4883

\section{Ingon Lee, Seokjun Hong, Hakjong You, Sung-Jun Hong, and Sang-Soo Kang}

Department of Anesthesiology and Pain Medicine, Kangdong Sacred Heart Hospital, Seoul, Korea

\begin{abstract}
A 15-year-old male patient presented with a slow progression of painless right shoulder weakness over the previous six weeks. The magnetic resonance imaging revealed right C4-5 foraminal stenosis caused by right foraminal disc protrusion. The needle electromyography and nerve conduction studies revealed acute $\mathrm{C} 5$ and/or $\mathrm{C} 6$ radiculopathy. Instead of the initial surgical management modalities, we performed a cervical epidural steroid injection at the C4-5 level. From the day after the patient received the cervical epidural steroid injection, his right shoulder motor weakness improved progressively. Two weeks after the procedure, his right shoulder motor function had fully recovered.
\end{abstract}

Keywords: Cervical; Epidural; Motor; Radiculopathy.
Cervical radiculopathy is a neurologic condition characterized by dysfunction of a cervical spinal nerve or the roots of the nerve, or both. It usually presents with pain in the neck and in one arm, and with a combination of sensory loss, loss of motor function, and/or reflex changes in the affected nerve root distribution [1]. The mechanisms that underlie radiculopathy are not well understood. Mechanical compression, chemical inflammation or irritation, and hypoxia of the nerve roots or dorsal ganglion have been proposed.

The main symptom of cervical radiculopathy is usually pain, and motor weakness is less frequent than pain. The treatment options for radicular pain include rest, analgesics, epidural steroid injection, and surgical treatments in cases of recalcitrant pain. In cases of radiculopathy with motor weakness, surgical treatment options are traditionally considered first.

We performed a literature review, and hereby report the case of a 15-year-old male patient who presented painless right shoulder weakness caused by $\mathrm{C} 4-5$ foraminal disc pro- trusion. As the right foraminal disc protrusion was not very severe, we suspect that the symptoms stemmed more from chemical irritation than from mechanical compression. The patient's motor function fully recovered after he received a cervical epidural steroid injection.

\section{CASE REPORT}

A 15-year-old male patient without underlying diseases presented with right shoulder weakness. This symptom had appeared after he had laid on a couch and slept 6 weeks prior. He had gone to another health care center and had received unknown analgesic medications, but the symptoms had progressively worsened.

At the time of his visit, his motor grade for right shoulder abduction and flexion was 2 , that for right shoulder extension was 4 , and that for right elbow flexion was 3 . His motor grades for right elbow extension, wrist flexion, and wrist extension were normal. His right shoulder motor grade was

This is an Open Access article distributed under the terms of the Creative Commons Attribution Non-Commercial License (http://creativecommons.org/licenses/by-nc/4.0) which permits unrestricted non-commercial use, distribution, and reproduction in any medium, provided the original work is properly cited.

Copyright (C) the Korean Society of Anesthesiologists, 2019 
evaluated using the British Medical Research Council grade. He complained of numbness in the right C5 dermatome area. The neurological examination showed that his biceps reflex, brachioradialis reflex, and triceps reflex were reduced. The laboratory examination and vital signs were unremarkable.

The magnetic resonance imaging revealed C4-5 foraminal stenosis caused by right foraminal disc protrusion (Fig. 1). We performed needle electromyography (EMG) and nerve conduction studies (NCS) (Fig. 2). In the NCS, the sensory and motor nerve conduction were normal. In the needle EMG, there was denervation potential in the resting state and a reduced recruitment pattern at maximal contraction in the right pronator teres, biceps brachii, deltoid, infraspinatus, supraspinatus, and paraspinal muscles. Although the C5 and C6 are difficult to localize due to an overlapping myotome, the results of the EMG and NCS suggested acute C5 or/and C6 radiculopathy in the right upper limb.

As the right C4-5 foraminal stenosis caused by the right foraminal disc protrusion was not very severe, we suspected that the symptoms stemmed more from chemical irritation than from mechanical compression. Therefore, we injected $2.5 \mathrm{mg}$ of dexamethasone (DEXA-S, Ilsung Pharmaceuticals, Korea) in the C4-5 epidural space by using interlaminar approach with the needle slightly pointing to the right (Fig. 3). Surgical treatment was planned in case there was no improvement in the patient's symptoms. However, from the day after he received the cervical epidural steroid injection, the patient's right shoulder motor weakness improved progressively. His right shoulder motor grade was 4 , and the numbness disappeared one week after the procedure. Two weeks after the cervical epidural steroid injection, his right shoulder motor function had fully recovered.

\section{DISCUSSION}

Cervical radiculopathy is commonly caused by mechanical compression or chemical irritation of a nerve root. A posteriorly protruding disk, osteophyte formation at the uncinate process and the zygophophyseal joint, and infolding of the ligamentum flavum and the facet joint capsule can cause pressure on the nerve root, triggering radicular symptoms. However, the exact pathogenesis of radicular pain is unclear. Besides mechanical compression, the intrinsic blood vessels show increased permeability within the compressed nerve root, which secondarily causes edema of the nerve root. Chronic edema of the nerve root can increase the sensitiv-
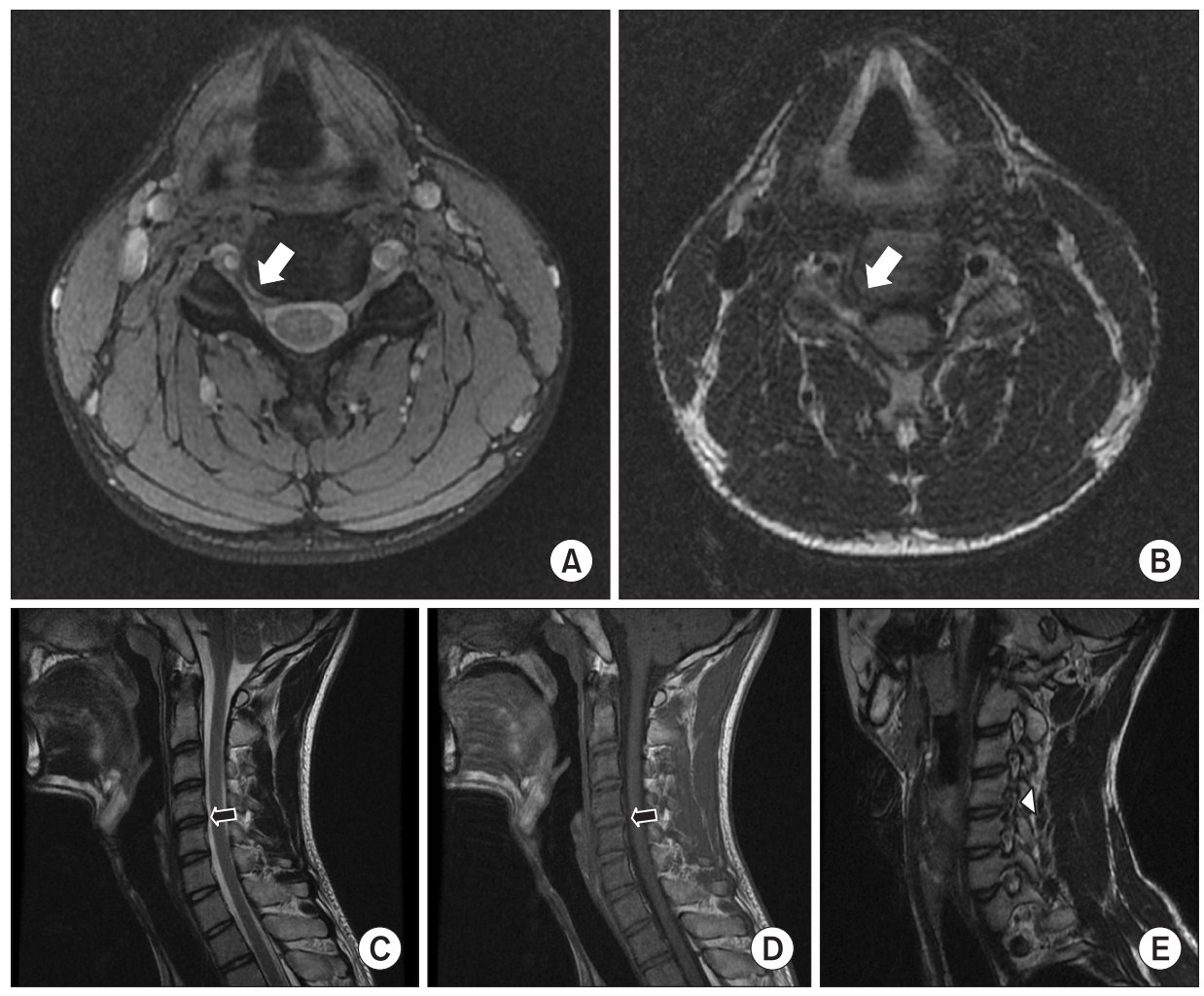

Fig. 1. C4-5 cervical spine magnetic resonance imaging. The T2-weighted axial (A) and T1-weighted axial views (B) show foraminal stenosis caused by disc protrusion (white arrow) in the right C4-5. The T2-weighted sagittal (C) and T1-weighted sagittal (D) views show mild disc protrusion in the right C4-5 (black arrow). In comparison with other foramens, there is more severe foraminal stenosis in the right C4-5 (arrowhead) on the T2-weighted right oblique view (E). 
A EMG

\begin{tabular}{|c|c|c|c|c|c|c|c|c|c|}
\hline Side & Muscle & Nerve & Root & Ins Act & Fibs & Psw & Amp & Int Pat & Comment \\
\hline Right & Abd Poll Brev & Median & C8-T1 & & & & & $P$ to $C$ & \\
\hline Right & Abd Dig Min & Ulnar & C8-T1 & & & & & $P$ to $C$ & \\
\hline Right & 1st Dorlnt & Ulnar & C8-T1 & & & & & $P$ to $C$ & \\
\hline Right & FlexCarRad & Median & C6-7 & & & & & $P$ to $C$ & \\
\hline Right & PronatorTeres & Median & C6-7 & & + & ++ & & Partial & \\
\hline Right & FlexCarpiUln & Ulnar & $\mathrm{C} 8, \mathrm{~T} 1$ & & & & & $P$ to $C$ & \\
\hline Right & ExtCarRadLong & Radial & C6-7 & & & & & $P$ to $C$ & \\
\hline Right & BrachioRad & Radial & C5-6 & & & & & $\mathrm{P}$ to $\mathrm{C}$ & \\
\hline Right & Biceps & Musculocut & C5-6 & & + & ++ & & Partial & \\
\hline Right & Triceps & Radial & C6-7-8 & & & & & $P$ to $C$ & \\
\hline Right & Deltoid & Axillary & C5-6 & & + & ++ & & Partial & \\
\hline Right & Infraspinatus & SupraScap & C5-6 & & + & ++ & & Partial & \\
\hline Right & Cervical Parasp Mid & Rami & C4-6 & & & & & & \\
\hline Right & Supraspinatus & SupraScap & C5-6 & & + & + & & Partial & \\
\hline Right & SerratAnt & LongThor & C5-7 & & & & & $\mathrm{P}$ to $\mathrm{C}$ & \\
\hline
\end{tabular}

B Nerve conduction studies: motor summary table

\begin{tabular}{|c|c|c|c|c|c|c|c|c|c|c|c|c|}
\hline Site & NR & $\begin{array}{l}\text { Onset } \\
\text { (ms) }\end{array}$ & $\begin{array}{c}\text { Norm } \\
\text { Onset } \\
(\mathrm{ms})\end{array}$ & $\begin{array}{l}\text { O-P } \\
\text { Amp } \\
(\mathrm{mV})\end{array}$ & $\begin{array}{c}\text { Norm } \\
\text { O-P } \\
\text { Amp }\end{array}$ & $\begin{array}{l}\text { Full area } \\
\text { (mV?ms) }\end{array}$ & Site 1 & Site 2 & \begin{tabular}{|c|} 
Delta-0 \\
(ms)
\end{tabular} & $\begin{array}{l}\text { Dist } \\
(\mathrm{cm})\end{array}$ & $\begin{array}{c}\mathrm{Vel} \\
(\mathrm{m} / \mathrm{s})\end{array}$ & $\begin{array}{c}\text { Norm } \\
\text { Vel } \\
(\mathrm{m} / \mathrm{s})\end{array}$ \\
\hline \multicolumn{13}{|c|}{ Left BPI Motor $27.5^{\circ} \mathrm{C}$} \\
\hline MCN & & 4.1 & & 3.6 & 12.11 & & & & & & & \\
\hline Axillary & & 3.4 & & 4.7 & 25.82 & & & & & & & \\
\hline Radial & & 4.5 & & 5.5 & 38.61 & & & & & & & \\
\hline \multicolumn{13}{|c|}{ Right BPI Motor $27.3^{\circ} \mathrm{C}$} \\
\hline Med, wirst & & 2.2 & & 8.5 & 30.60 & & Med, wirst & Med, elbow & 4.1 & 24.0 & 59 & \\
\hline Med, elbow & & 6.3 & & 7.7 & 29.57 & & UI, wirst & Ul, elbow & 4.2 & 24.0 & 57 & \\
\hline Ul, wirst & & 1.7 & & 7.9 & 27.71 & & & & & & & \\
\hline Ul, elbow & & 5.9 & & 6.4 & 24.26 & & & & & & & \\
\hline $\mathrm{MCN}$ & & 4.6 & & 3.0 & 34.43 & & & & & & & \\
\hline Axillary & & 3.8 & & 4.1 & 19.34 & & & & & & & \\
\hline Radial & & 4.8 & & 3.2 & 24.81 & & & & & & & \\
\hline \multicolumn{13}{|c|}{ Right C-rad Motor $27.8^{\circ} \mathrm{C}$} \\
\hline Axillary, Lt. & & 3.7 & & 2.0 & 4.53 & & & & & & & \\
\hline MCN, Lt. & & 3.2 & & 1.0 & 2.44 & & & & & & & \\
\hline MCN, Rt. & & 4.9 & & 1.6 & 10.79 & & & & & & & \\
\hline Axillary, Rt. & & 4.1 & & 1.6 & 5.03 & & & & & & & \\
\hline Infraspinatus, Rt. & & 3.4 & & 3.2 & 16.07 & & & & & & & \\
\hline Infraspinatus, Lt. & & 3.1 & & 3.7 & 11.93 & & & & & & & \\
\hline
\end{tabular}

Fig. 2. Needle electromyography and nerve conduction studies. In the needle elecdtromyography (A), there are denervation potential in the resting state and a reduced recruitment pattern at maximal contraction in the right pronator teres, biceps brachii, deltoid, infraspinatus, supraspinatus, and paraspinal muscles. In the nerve conduction studies, the motor (B) and sensory (C) nerve conduction are normal. Ins Act: insertional activity, Fibs: fibrillations, Psw: positive sharp waves, Amp: amplitude, Int Pat: interference pattern, Norm: normal, Dist: distance, Vel: velocity, ABD: abductor, BPI: brachial plexus injury, MCN: musculocutaneous, Med: median, Ul: ulnar, Lt.: left, Rt.: right, MABC: medial antebrachial cutaneous, LABC: lateral antebrachial cutaneous, Sup: supraspinatus, rad: radial.

ity of the nerve root to pain [2]. The neurogenic chemical mediators of pain released by the cell bodies of the sensory neurons and the non-neurogenic mediators released by disc tissue may play a role in the initiation and maintenance of this inflammatory response [3]. Moreover, the dorsal root ganglion is a key agent of radicular pain. As the membrane of the dorsal root ganglion is more permeable than that around the nerve root, it enables a more florid local inflammatory response [4]. This is the rationale for treatment with antiinflammatory medications [5]. Moreover, the focal compression at the entrance of the neural foramen caused by the mild posteriorly protruding disk, uncovertebral joint arthrosis with or without soft-tissue pathologies can produce isolated lesion of the motor ventral nerve root. This anterior focal compression does not affect the sensory and nociceptive dorsal nerve root or dorsal root ganglion, the motor weakness without concomitant pain or sensory of upper limbs can occur [6].

In most cases, the patient's history and physical examinations are sufficient to make a diagnosis [7]. Patients typically present with neck and arm pain, and these sensory symptoms usually follow a dermatomal distribution. The sensory symptoms include a burning or tingling sensation, and they 
C Nerve conduction studies: sensory summary table

\begin{tabular}{|c|c|c|c|c|c|c|c|c|c|c|c|c|c|}
\hline Site & NR & $\begin{array}{c}\text { Onset } \\
\text { (ms) }\end{array}$ & $\begin{array}{c}\text { Peak } \\
\text { (ms) }\end{array}$ & $\begin{array}{c}\text { Norm } \\
\text { Peak } \\
(\mathrm{ms})\end{array}$ & $\begin{array}{c}\text { P-T } \\
\text { Amp } \\
(\mu \mathrm{V})\end{array}$ & $\begin{array}{c}\text { Norm } \\
\text { P-T } \\
\text { Amp }\end{array}$ & $\begin{array}{l}\text { Full area } \\
(\mu \vee ? \mathrm{~ms})\end{array}$ & Site 1 & Site 2 & \begin{tabular}{|c|} 
Delta-P \\
(ms)
\end{tabular} & $\begin{array}{l}\text { Dist } \\
(\mathrm{cm})\end{array}$ & $\begin{array}{l}\mathrm{Vel} \\
(\mathrm{m} / \mathrm{s})\end{array}$ & $\begin{array}{c}\text { Norm } \\
\text { Vel } \\
(\mathrm{m} / \mathrm{s})\end{array}$ \\
\hline \multicolumn{14}{|c|}{ Left BPI Motor $27.5^{\circ} \mathrm{C}$} \\
\hline MABC & & 1.3 & 1.8 & & 12.2 & & 110.24 & & & & & & \\
\hline LABC & & 1.4 & 1.9 & & 26.5 & & 10.24 & & & & & & \\
\hline MABC & & 1.7 & 2.1 & & 19.2 & & 16.68 & & & & & & \\
\hline \multicolumn{14}{|c|}{ Right BPI Anti Sensory $27.6^{\circ} \mathrm{C}$} \\
\hline Supf, rad & & 2.1 & 2.7 & & 32.6 & & 34.49 & & & & & & \\
\hline 1st, med & & 2.0 & 2.4 & & 71.7 & & 30.93 & & & & & & \\
\hline 2nd, med & & 2.3 & 2.9 & & 75.6 & & 45.68 & & & & & & \\
\hline 5th, UI & & 2.1 & 2.7 & & 63.9 & & 33.44 & & & & & & \\
\hline MABC & & 2.1 & 2.6 & & 16.1 & & 7.98 & & & & & & \\
\hline LABC & & 1.6 & 2.1 & & 29.5 & & 12.35 & & & & & & \\
\hline \multicolumn{14}{|c|}{ Right C-rad Anti Sensory $28.7^{\circ} \mathrm{C}$} \\
\hline Supf, rad & & 1.8 & 2.3 & & 45.2 & & 23.02 & & & & & & \\
\hline LABC & & 1.8 & 2.6 & & 59.7 & & 261.82 & & & & & & \\
\hline 1st, sup rad & & 2.0 & 2.5 & & 20.6 & & 10.15 & & & & & & \\
\hline 2nd, med & & 2.3 & 2.9 & & 61.9 & & 37.33 & & & & & & \\
\hline 1st, med & & 2.0 & 2.5 & & 63.3 & & 27.35 & & & & & & \\
\hline 1st, med, Lt & & 1.6 & 2.3 & & 89.7 & & 37.04 & & & & & & \\
\hline 2nd, med, Lt & & 2.2 & 2.7 & & 81.2 & & 50.45 & & & & & & \\
\hline Supf, rad, Lt & & 1.4 & 1.9 & & 47.0 & & 22.57 & & & & & & \\
\hline $\mathrm{LABC}, \mathrm{Lt}$ & & 1.8 & 2.3 & & 47.1 & & 28.16 & & & & & & \\
\hline
\end{tabular}

Fig. 2. Continued.
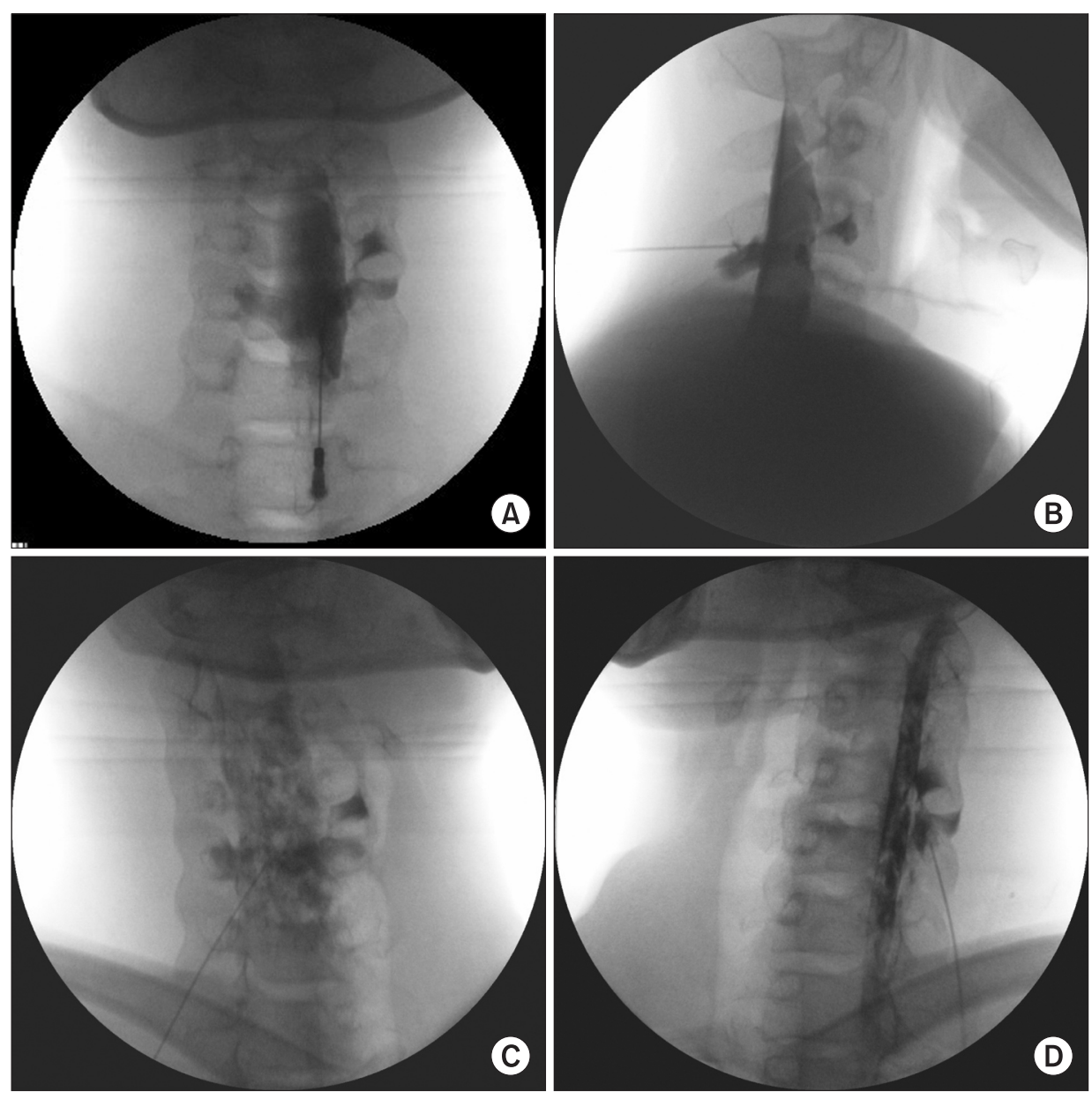

Fig. 3. Epidural steroid injection in right $44-5$. The epidural space was confirmed with contrast media in the antero-posterior $(A)$, sagittal $(B)$, right oblique $(C)$, and left oblique $(D)$ views. 
are usually aggravated by extension or lateral rotation of the head to the side of the pain. Subjective weakness of the arm or hand is also occasionally reported, for example trapezius and supraspinatus/infraspinatus muscle for $\mathrm{C} 4$, deltoid muscle for $\mathrm{C} 5$, biceps and brachioradialis muscle for $\mathrm{C} 6$, triceps muscle for $\mathrm{C} 7$, hypothenar muscles for $\mathrm{C} 8$, interosseous muscles for C8 and T1 [1]. Henderson et al. [8] reviewed the clinical presentations of cervical radiculopathy in 736 patients: 99.4\% had arm pain, $85.2 \%$ had sensory deficits, $79.7 \%$ had neck pain, $71.2 \%$ had reflex deficits, $68 \%$ had motor deficits, $52.5 \%$ had scapular pain, $17.8 \%$ had anterior chest pain, $9.7 \%$ had headaches, $5.9 \%$ had anterior chest and arm pain, and $1.3 \%$ had left-sided chest and arm pain or cervical angina.

Imaging modalities are commonly used to assist the diagnosis of cervical radiculopathy. MRI is the imaging modality of choice for its assessment. However, there are no clear guidelines about when to obtain these images. Conventional radiographs have a low radiographic sensitivity for the detection of tumors or infections, and are unable to detect disk herniation. They have a limited value for the finding of cervical intervertebral narrowing to predict nerve root or cord compression [9]. Computed tomography can be useful for the detection of bony spurs, osseous contribution to the foraminal encroachment, and the ossification of the posterior longitudinal ligament.

EMG and NCS may be helpful to rule out brachial plexopathy or other neurologic causes of neck and arm pain. Within three weeks of the onset of nerve compression, positive sharp-wave potentials and fibrillation potentials typically present in the limb muscles of the involved myotome [10]. The accuracy of EMG was evaluated in 77 patients with cervical radiculopathy and/or myelopathy in the preoperative period. In $57 \%$ of the patients, the affected root level could be determined, while $10 \%$ showed a non-specific finding, and the EMG was normal in $33 \%$ of the patients. Therefore, EMG plays a complementary role in the diagnosis of cervical radiculopathy [11].

Various neurological diseases can cause progressive painless motor weakness of upper limbs.

The differential diagnoses include the cervical motor radiculopathy due to foraminal stenosis, amyotrophic lateral sclerosis (ALS), spinal muscular atrophy type IV, multifocal motor neuropathy (MMN), hereditary neuropathy with liability to pressure palsies (HNPP), and entrapment syndromes of cervical plexus and/or peripheral nerves [6]. In this case, we excluded ALS and spinal muscular atrophy type IV because the patient presented with segmental lesion (deltoid muscle weakness), and MMN, HNPP and the entrapment syndromes because the sensory and motor nerve conduction were normal in NCSs.

In patients presenting with cervical radiculopathy without myelopathy or motor weakness, conservative treatment should be attempted before surgery. This approach is based on the natural history of cervical radiculopathy. Wong et al. [12] performed a systemic review of the course and prognostic factors in patient with cervical disc herniation with radiculopathy. In their study, substantial improvements tended to occur within the first four to six months after the onset. In approximately $83 \%$ of patients, complete recovery was achieved within 24 to 36 months. However, for cervical radiculopathy without myelopathy, surgery is typically recommended when all of the following are present: definite cervical root compression visualized on the MRI; concordant symptoms and signs of cervical root-related dysfunction; pain and persistence of the pain despite nonsurgical treatment for at least six to twelve weeks or the presence of a progressive, functionally important motor deficit [1].

The main symptom of cervical radiculopathy is usually pain, and the incidence of motor weakness is lower than that of pain. In this case-unlike in most cases-, the patient presented with motor weakness that had acutely worsened over the previous six weeks, without pain. Based on a cervical MRI and EMG, we suspected cervical radiculopathy, and considered that the radiculopathy had developed from chemical irritation rather than from mechanical compression, as the MRI images only showed mild right $\mathrm{C} 4-5$ foraminal stenosis. We injected dexamethasone-a drug with an antiinflammatory effect- in the C4-5 epidural space by using interlaminar approach with the needle slightly pointing to the right to improve the patient's symptoms by targeting the neurogenic and non-neurogenic chemical mediators prior to surgical decompression. Epidural steroid injection is an effective treatment method by injecting anti-inflammatory medication into the perineural environment of the affected nerve root [13]. His motor weakness improved dramatically from the day after the epidural injection. We think the patient had good outcome as we performed epidural steroid injection at a relatively early period of six weeks after the onset of 
symptoms.

In conclusion, in radiculopathy with motor weakness that aggravates acutely, an accurate diagnosis should be made using MRI images and EMG in addition to the patient's medical history and physical examinations. We think that a cervical epidural steroid injection can be chosen first as a therapeutic option than surgery in such cases.

\section{CONFLICTS OF INTEREST}

No potential conflict of interest relevant to this article was reported.

\section{ORCID}

Ingon Lee: https://orcid.org/0000-0001-7752-9445

Seokjun Hong: https://orcid.org/0000-0001-6071-5022

Hakjong You: https://orcid.org/0000-0001-9817-8891

Sung-Jun Hong: https://orcid.org/0000-0002-2466-718X

\section{REFERENCES}

1. Carette S, Fehlings MG. Clinical practice. Cervical radiculopathy. N Engl J Med 2005; 353: 392-9.

2. Cooper RG, Freemont AJ, Hoyland JA, Jenkins JP, West CG, Illingworth KJ, et al. Herniated intervertebral disc-associated periradicular fibrosis and vascular abnormalities occur without inflammatory cell infiltration. Spine (Phila Pa 1976) 1995; 20: 591-8.

3. Chabot MC, Montgomery DM. The pathophysiology of axial and radicular neck pain. Semin Spine Surg 1995; 7: 2-8.

4. Rao R. Neck pain, cervical radiculopathy, and cervical myelopa- thy: pathophysiology, natural history, and clinical evaluation. Instr Course Lect 2003; 52: 479-88.

5. Woods BI, Hilibrand AS. Cervical radiculopathy: epidemiology, etiology, diagnosis, and treatment. J Spinal Disord Tech 2015; 28: E251-9.

6. Siller S, Kasem R, Witt TN, Tonn JC, Zausinger S. Painless motor radiculopathy of the cervical spine: clinical and radiological characteristics and long-term outcomes after operative decompression. J Neurosurg Spine 2018; 28: 621-9.

7. Honet JC, Ellenberg MR. What you always wanted to know about the history and physical examination of neck pain but were afraid to ask. Phys Med Rehabil Clin N Am 2003; 14: 473-91.

8. Henderson CM, Hennessy RG, Shuey HM Jr, Shackelford EG. Posterior-lateral foraminotomy as an exclusive operative technique for cervical radiculopathy: a review of 846 consecutively operated cases. Neurosurgery 1983; 13: 504-12.

9. Pyhtinen J, Laitinen J. Cervical intervertebral foramen narrowing and myelographic nerve root sleeve deformities. Neuroradiology 1993; 35: 596-7.

10. Han JJ, Kraft GH. Electrodiagnosis of neck pain. Phys Med Rehabil Clin N Am 2003; 14: 549-67.

11. Partanen J, Partanen K, Oikarinen H, Niemitukia L, Hernesniemi J. Preoperative electroneuromyography and myelography in cervical root compression. Electromyogr Clin Neurophysiol 1991; 31:21-6.

12. Wong JJ, Côté P, Quesnele JJ, Stern PJ, Mior SA. The course and prognostic factors of symptomatic cervical disc herniation with radiculopathy: a systematic review of the literature. Spine J 2014; 14: 1781-9.

13. Byeon GJ, Choi EJ, Choi YM, Chang EJ, Kim HJ, Kim KH. Oblique interlaminar lumbar epidural steroid injection for management of low back pain with lumbosacral radicular pain: a case report. Anesth Pain Med 2017; 12: 375-80. 